University of Nebraska - Lincoln

DigitalCommons@University of Nebraska - Lincoln

Faculty Publications from the Department of Electrical \& Computer Engineering, Department Electrical and Computer Engineering

5-1-1989

\title{
Radio-frequency plasma chemical vapor deposition growth of diamond
}

\author{
Duane E. Meyer \\ University of Nebraska-Lincoln \\ Rodney O. Dillon \\ University of Nebraska-Lincoln, rdillon2@unl.edu \\ John A. Woollam \\ University of Nebraska-Lincoln, jwoollam1@unl.edu
}

Follow this and additional works at: https://digitalcommons.unl.edu/electricalengineeringfacpub

Part of the Electrical and Computer Engineering Commons

\footnotetext{
Meyer, Duane E.; Dillon, Rodney O.; and Woollam, John A., "Radio-frequency plasma chemical vapor deposition growth of diamond" (1989). Faculty Publications from the Department of Electrical and Computer Engineering. 68.

https://digitalcommons.unl.edu/electricalengineeringfacpub/68
}

This Article is brought to you for free and open access by the Electrical \& Computer Engineering, Department of at DigitalCommons@University of Nebraska - Lincoln. It has been accepted for inclusion in Faculty Publications from the Department of Electrical and Computer Engineering by an authorized administrator of DigitalCommons@University of Nebraska - Lincoln. 


\title{
Radio-frequency plasma chemical vapor deposition growth of diamond
}

\author{
Duane E. Meyer, Rodney O. Dillon, and John A. Woollam \\ Department of Electrical Engineering, Center for Microelectronic and Optical Materials Research. \\ University of Nebraska, Lincoln, Nebraska 68588-0511
}

(Received 14 December 1988; accepted 16 January 1989)

\begin{abstract}
Plasma chemical vapor deposition (CVD) at $13.56 \mathrm{MHz}$ has been used to produce diamond particles in two different inductively coupled systems with a mixture of methane and hydrogen. The effect of a diamondlike carbon (DLC) overcoating on silicon, niobium, and stainless-steel substrates has been investigated and in the case of silicon has been found to enhance particle formation as compared to uncoated polished silicon. In addition the use of carbon monoxide in hydrogen has been found to produce well-defined individual faceted particles as well as polycrystalline films on quartz and DLC coated silicon substrates. Plasma CVD is a competitive approach to production of diamond films. It has the advantage over microwave systems of being easily scaled to large volume and high power.
\end{abstract}

\section{INTRODUCTION}

Production of diamond from the gas phase has become an important research topic of international interest. Much recent work is with microwave plasmas, and filament assisted CVD. ${ }^{1.2}$ However, 13.56-MHz rf plasmas are an important alternative technology offering attractive options, including easy scalability of volume and power.

Potential applications of diamond films are numerous and include their use in heat sinks, high-temperature semiconductor devices, optical windows, and abrasives.

In this paper we discuss operation of two different 13.56$\mathrm{MHz}$ plasma deposition systems, one with up to 500-W rf power, and the second with up to $3-\mathrm{kW}$ power.

\section{EXPERIMENTAL}

\section{A. Apparatus}

The first system had a quartz reaction tube with a $1.4-\mathrm{cm}$ diameter and $30-\mathrm{cm}$ length. The rf was inductively coupled to $\mathrm{CH}_{4} / \mathrm{H}_{2}$ plasma. The maximum power from this system was $500 \mathrm{~W}$. Deposition parameters varied but typically a $0.5 \%$ methane in hydrogen gas mixture was used at 20 Torr with substrate temperatures ranging from $<700$ to $1000^{\circ} \mathrm{C}$. Substrate heating in this system was accomplished by placing the substrate on a graphite susceptor.

The second system was similar to the first, but with a maximum input power of $3 \mathrm{~kW}$ available. The quartz reaction tube in this system was $2.8 \mathrm{~cm}$ in diameter and $40 \mathrm{~cm}$ in length. Substrate temperatures ranged from 850 to $950^{\circ} \mathrm{C}$. Substrate heating in this system was accomplished by inductive heating. This limited input powers to the range from 650 to $950 \mathrm{~W}$. Gas mixtures of methane in hydrogen and carbon monoxide in hydrogen were used. In both systems, substrate temperatures were measured using an optical pyrometer, and gas flow rates were measured using mass flow controllers. Deposition pressures ranged from 20 to 40 Torr in the 3$\mathrm{kW}$ system.

\section{B. Substrates}

In the 500-W system almost all the substrates were silicon wafers and these were either polished or roughened by sand- paper, sandblasting, or silicon wafer to silicon wafer abrasion. Substrates were cleaned by sonicating in trichloroethylene and acetone.

In the 3-kW system silicon wafers were either scratched, as in the 500-W system, or they were coated with diamondlike carbon (DLC). DLC coated substrates were produced in a separate chamber with a capacitively coupled rf discharge of $80 \%$ methane, $20 \%$ argon at 40 Torr. DLC is an amorphous, hard, semitransparent carbon containing roughly $20 \%-50 \%$ hydrogen. ${ }^{3}$ In addition, substrates of niobium, stainless steel (both coated and uncoated with DLC), and quartz were used.

\section{RESULTS}

\section{A. 500-W system}

Figure 1 is a micrograph of a typical deposit on a scratched silicon substrate grown with a substrate temperature of $\sim 900^{\circ} \mathrm{C}$. By careful examination it was discovered that under each particle was a pedestal. By scanning Auger microprobe (SAM) spectroscopy it was determined that the pedestals were composed of graphitic carbon (Fig. 2). Thus the particles were nucleating on graphitic carbon rather than directly on the silicon wafer substrate. The sample shown in

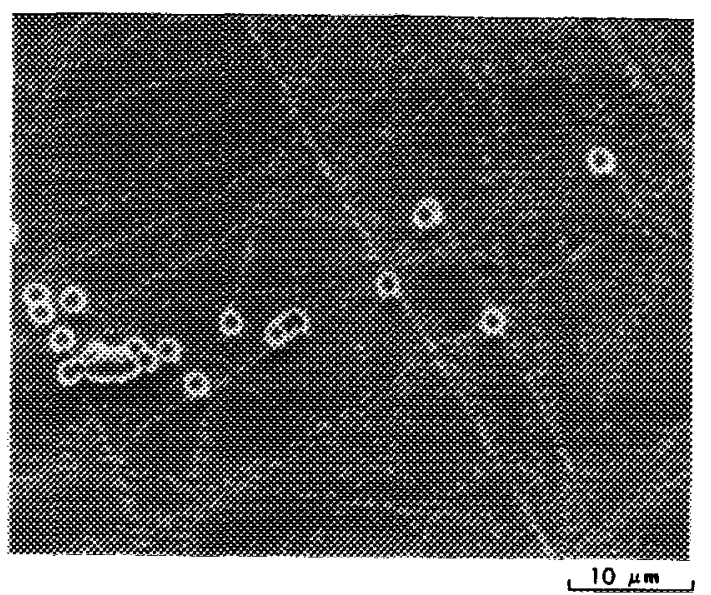

FIG. 1. Micrograph illustrating the presence of pedestals under particles. 


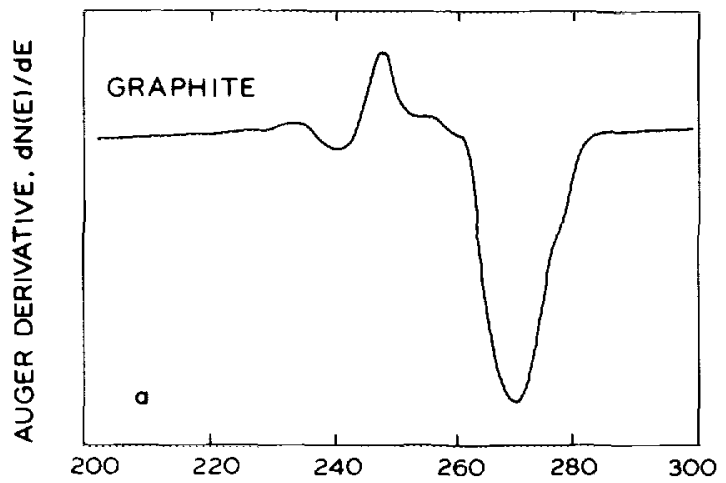

(a)

KINETIC ENERGY, QV

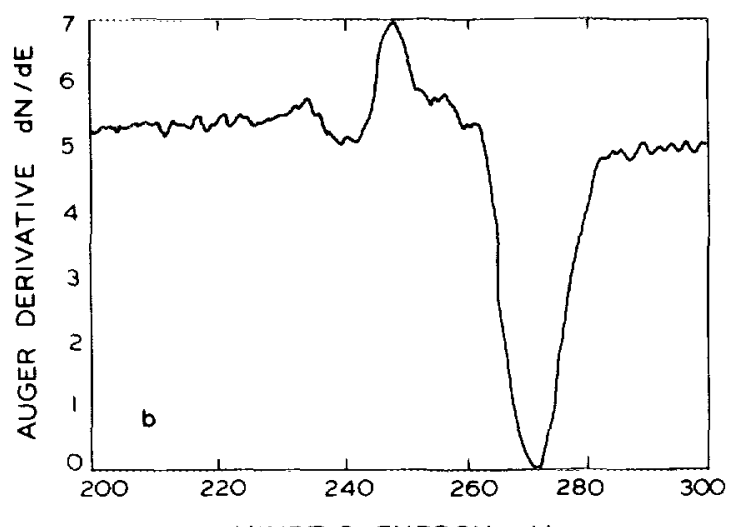

(b)

KINETIC ENERGY, QV

FIG. 2. SAM C KLL spectra of (a) high-purity graphite and (b) pedestal. After Williams, Moravec, and Orent (Ref. 4).

Fig. 1 was grown with $0.5 \%$ methane in hydrogen and 500 $\mathrm{W}$ power for $2 \mathrm{~h}$. In this system, this type of deposit always occurred when substrates were heated to temperatures ranging from 850 to $1000^{\circ} \mathrm{C}$. However, when no substrate heating was used (we estimate substrate temperatures were $700^{\circ} \mathrm{C}$ or less) faceted deposits were obtained. Scanning Auger microprobe spectroscopy of the faceted particles exhibited the $C K L L$ line shape typical of diamond. A more detailed report of the results from this system have been reported elsewhere. ${ }^{5}$

\section{B. 3-kW system}

From the results of depositions using the 500 -W system, it was postulated that coating silicon substrates with DLC could promote the deposition of diamond. Experiments were made using the 3-kW system to compare depositions on scratched and DLC coated silicon. Figure 3 shows scanning electron micrographs of deposits on scratched and DLC coated silicon. These indicate that particles could be deposited on DLC coated silicon with nucleation densities similar to that of scratched silicon. However, the particle size was more uniform on the DLC coated silicon than on the scratched substrates. Both depositions in Fig. 3 were made using $1.2 \%$ methane in hydrogen at $\sim 40$ Torr with an input power of $800 \mathrm{~W}$. The substrate temperature was measured to be $\sim 950^{\circ} \mathrm{C}$. The deposition time using DLC on silicon was $72 \mathrm{~h}$ while that of the scratched silicon was $96 \mathrm{~h}$. These results support recent observations by Ravi et al. ${ }^{6}$ that DLC promotes diamond nucleation in DC biased systems.

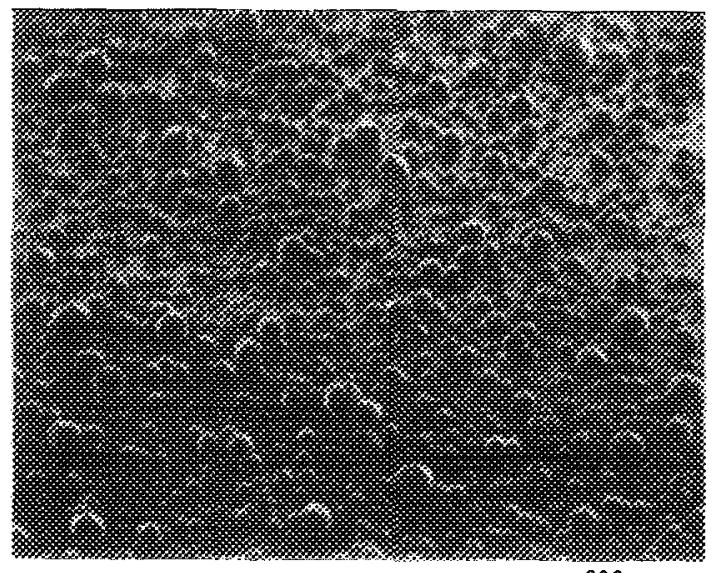

$200 \mu \mathrm{m}$

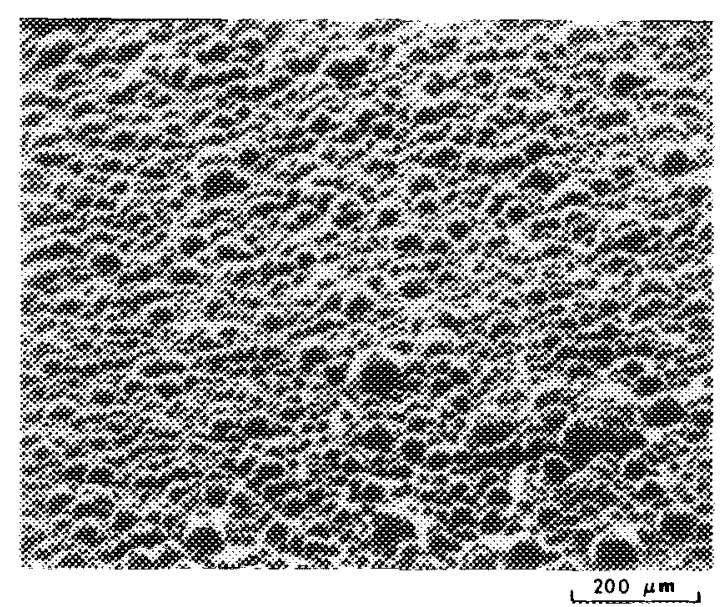

FIG. 3. Micrographs of deposits on (a) a scratched silicon substrate and (b) a DLC coated substrate.

Recent experiments were performed using uncoated and DLC coated niobium and stainless-steel. The niobium results indicate that the DLC coating improved particle formation. The deposits on two stainless-steel substrates were so dense that no difference could be detected between the uncoated and DLC coated substrates. For these runs, depositions were made using $2 \%$ methane with $0.5 \%$ oxygen in hydrogen at $\sim 40$ Torr with an input power of $650 \mathrm{~W}$. Substrate temperatures were $\sim 880^{\circ} \mathrm{C}$ and deposition times ranged from 16 to $48 \mathrm{~h}$. Depositions under these conditions produced spherically shaped particles.

Investigations of the effect of a DLC overcoat on niobium and stainless-steel substrates are continuing.

We also have recently begun investigations using $5 \%$ carbon monoxide in hydrogen as a source gas. This has produced well-defined individual faceted particles as well as polycrystalline films on quartz and DLC coated silicon substrates. The deposition illustrated in Fig. 4 was made using a DLC coated silicon substrate at 30 Torr. A substrate temperature of $\sim 890^{\circ} \mathrm{C}$ was measured with an input power of $750 \mathrm{~W}$. The deposition time was $24 \mathrm{~h}$.

\section{CONCLUSIONS}

In both systems faceted particles have been deposited on silicon substrates. However, with approximately the same 


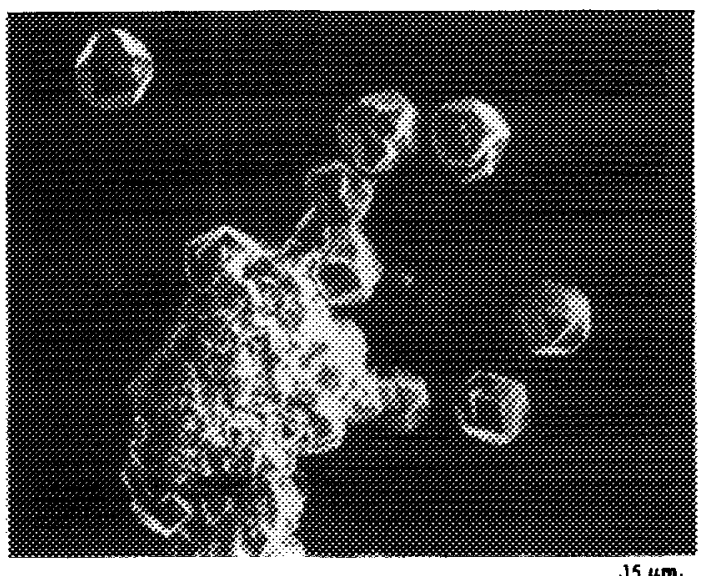

$15 \mu \mathrm{m}$

FIG. 4. Micrograph of deposits obtained using $5 \% \mathrm{CO}$ in $\mathrm{H}_{2}$

methane concentration, deposition temperatures which produced faceted particles in the $3-\mathrm{kW}$ system would only produce "egg-shaped" particles in the 500-W system. This may be due to the presence of the graphite susceptor, or to a noticably more intense plasma, in the $500-W$ system. The formation of faceted particles on DLC coated silicon substrates with nucleation densities similar to that obtained for scratched silicon substrates has been observed in the $3-\mathrm{kW}$ system. This indicates that the formation of diamond on sili- con is enhanced by a DLC overcoat when compared to polished substrates in the systems described here. Recent results indicate that DLC overcoating enhances particle formation on niobium but this may not be the case for stainless-steel substrates and further investigation is needed. Well-defined individual faceted particles as well as polycrystalline films have been obtained on quartz and DLC coated silicon substrates using $5 \%$ carbon monoxide in hydrogen.

\section{ACKNOWLEDGMENTS}

This work was supported by the Center for Microelectronic and Optical Materials Research (State of Nebraska) and in part by NASA Lewis Grant No. NAG 3-95 and a grant from Applied Science in Yellow Springs, $\mathrm{OH}$. We would like to acknowledge the contributions of the data in Fig. 2(b) by our colleagues at SERI (see Ref. 5).

'SPIE Symp. Proc. 969 (1989).

'Diamond and Diamond-Like Materials Synthesis, MRS Extended Abstracts, edited by G. H. Johnson, A. R. Badzian, and M. W. Geis (MRS, Pittsburgh, PA, 1988).

'J. C. Angus, P. Koidl, and S. Domitz, "Carbon Thin Films," in Plasma Deposited Thin Films, edited by J. P. Mort and F. P. Jansen (CRC, Boca Raton, FL, 1986).

${ }^{4}$ T. J. Moravec and T. W. Orent, J. Vac. Sci. Technol 18, 226 (1981).

${ }^{5}$ D. E. Meyer, N. J. Ianno, J. A. Woollam, A. B. Swartzlander, and A. J. Nelson, J. Mater. Res. 3, 1397 (1988).

'K. V. Ravi, M. Peters, L. Plano, and M. Pinneo, paper T21 presented at the SDIO/IST-ONR Diamond Technology Initiative Symposium, Crystal City, Arlington, VA, 1988. 